\title{
Far Lateral Disk Prolapsed: a Preliminary Experience by Percutaneous Endoscopic Approach
}

\author{
Leonello Tacconi* and Paolo Bobicchio \\ Neurosurgical Unit, Azienda Universitaria Integrata, Italy
}

Submission: February 24, 2018; Published: March 14, 2018

*Corresponding author: Leonello Tacconi, FRCS Ed (SN), Neurosurgical Unit, Azienda Universitaria Integrata, Strada di Fiume, 447, Trieste, Italy, Fax: 0039-040-399-4057; Email: leonello.tacconi@asuits.sanita.fvg.it

\begin{abstract}
Background: The endoscopic approach has been introduced in the clinical practice in 1980 with the aim to remove the prolapsed disk and free the compressed nerve using the least disruptive surgical technique and assuring the resolution of the symptoms and a faster return back to full life activities.

Methods: We retrospectively selected 22 patients operated on for a far lateral lumbar disk prolapsed between January 2011 and December 2016. Thirteen underwent a far lateral microsurgical approach while the rest, nine, a far lateral endoscopic approach.

Results: After surgery all the patients were fine with an improvement of the symptoms by Visual Analogue Scale and Oswestry Disability Index. One patient had to be operated again for persistent pain secondary to an unsatisfactory disk removal. All patients went home within four days and at a median follow up of 12 months (range between 7 and 17 months) all patients had improved and were back to a normal life.

Conclusion: The endoscopic procedure is safe, effective and may become the treatment of choice for any type of lumbar disk prolapsed including also the far lateral location.
\end{abstract}

Keywords: Far lateral disk; Endoscopic approach; Ganglion; Transverse process

\section{Introduction}

Since the introduction of the endoscopic technique in the neurosurgical field in 1980, we have assisted to major changes with regard to the treatment of lumbar disk prolapsed with the aim to minimize as much as possible the surgical act towards a technique very minimally invasive and the least disruptive for the surrounding tissues [1-3]. It has been possible to achieve this goal thanks to the extraordinary technical improvement in the endoscopic field occurred in the last few years. The endoscopic technique is undoubtly a useful method to reach and remove the prolapsed disk and has also proven to be very effective with a low recurrence rate [4]. Unfortunately a certain amount of lumbar disk protrusion may occur in a location difficult to be reached by a traditional approach. These are those disks localized just outside the foramen: the so called far lateral or extra foraminal disk protrusion. In our Unit we have started to implement the use of the endoscope in disk prolapsed surgery in 2015 and only after we have overcome the initial learning curve phase we have applied this technique for far lateral disk as well.

\section{Material and Methods}

From January 2011 and December 2016 we have operated 22 extra foraminal disk prolapsed. Thirteen had undergone a lateral microsurgical approach; eight a percutaneous lateral endoscopic approach. Fourteen were at L4-L5 with 5 endoscopic procedure and eight at L3-L4 (4 endoscopic procedures). In the lateral microsurgical approach we have 10 females and 5 males. The median age was 45 years with a range between 25 and 56 years. Regarding the endoscopic group five were male and three females. The median age was 38.5 with a range between 23 and 54 (Table $1 \& 2$ ). The duration of symptoms were similar in both group as well as the severity of pain with a median VAS of 7 in the endoscopic and 8 in the microsurgical group. All the patients had been followed up at intervals of $1 ; 3 ; 6 ; 12$ months with Visual Analogue Scale (VAS) and Oswestry Disability Index (ODI). The different choice of approach was mainly due by the surgeons preference as well as by the fact that the endoscopic technique has been introduced in our Unit only in the last 3 years.

Table 1: Disks location.

\begin{tabular}{|c|c|c|}
\hline $\begin{array}{c}\text { Extra Foraminal } \\
\text { Disks }\end{array}$ & $\begin{array}{c}\text { Lateral } \\
\text { Microsurgical } \\
\text { Approach }\end{array}$ & $\begin{array}{c}\text { Percutaneous } \\
\text { Lateral (far } \\
\text { lateral) Endoscopic } \\
\text { Approach }\end{array}$ \\
\hline 22 & 13 & 9 \\
\hline
\end{tabular}


Table 2: Clinical Series.

\begin{tabular}{|c|c|c|c|}
\hline $\begin{array}{c}\text { January } \\
\text { 2011-December } \\
\mathbf{2 0 1 6}\end{array}$ & Total Cases & $\begin{array}{c}\text { Microsurgical } \\
\text { Procedures }\end{array}$ & $\begin{array}{c}\text { Endoscopic } \\
\text { Procedures }\end{array}$ \\
\hline & $\mathbf{2 2}$ & $\mathbf{1 3}$ & $\mathbf{9}$ \\
\hline & Females & 9 & 4 \\
\hline & Males & 4 & 5 \\
\hline & Median Age & 45 & 38,3 \\
\hline & Range & $25-56$ years & $23-54$ years \\
\hline Levels & & & \\
\hline L3-L4 & 8 & 4 & 4 \\
\hline L4-L5 & 14 & 9 & 5 \\
\hline
\end{tabular}

\section{Surgical Technique}

The patients is placed prone on a standard operative table. All the procedures are performed under general anesthesia (GA) and no muscles relaxant is used. Skin entry point, about $10-12 \mathrm{~cm}$ laterally to the midline, is calculated by A-P and lateral $\mathrm{X}$-rays. An 18 gauge needle ( $21 \mathrm{~cm}$ length) is inserted under $\mathrm{X}$-ray guidance such that the tip's needle lies against the bone, at the outside superior lateral border of the pedicle (caudal part of the foramen) in the lateral x-ray view (Figure 1), without crossing the lateral pedicle line in the anterior-posterior projection. A soft wire guide is then advanced inside the needle until it reaches the bone. At this point a thin tube is inserted along the k-wire. This tube is hammered a few mm inside the bone in order to give a certain degree of stability.

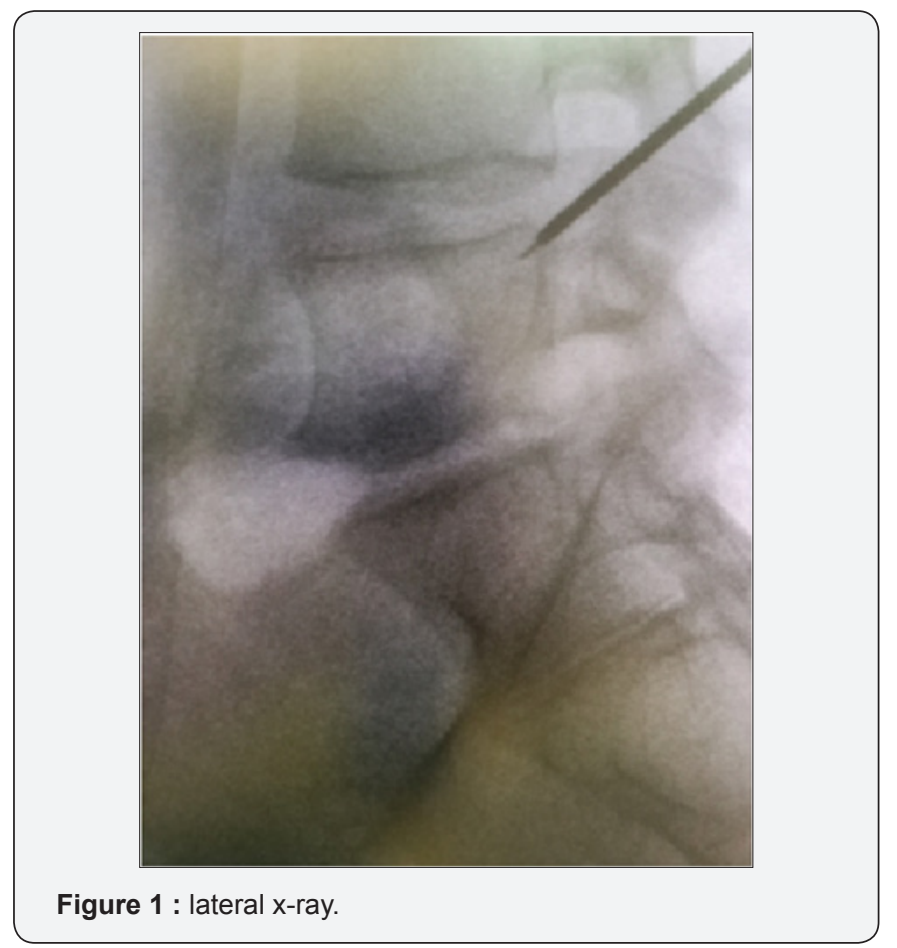

Then, progressive bigger dilators are passed over each other and eventually the working tube is introduced under $x$-ray control. Finally the surgeon introduces the endoscope through the working tube and tray to identify the surrounding structures such as the caudal, lateral and ventral portion of the foramen.

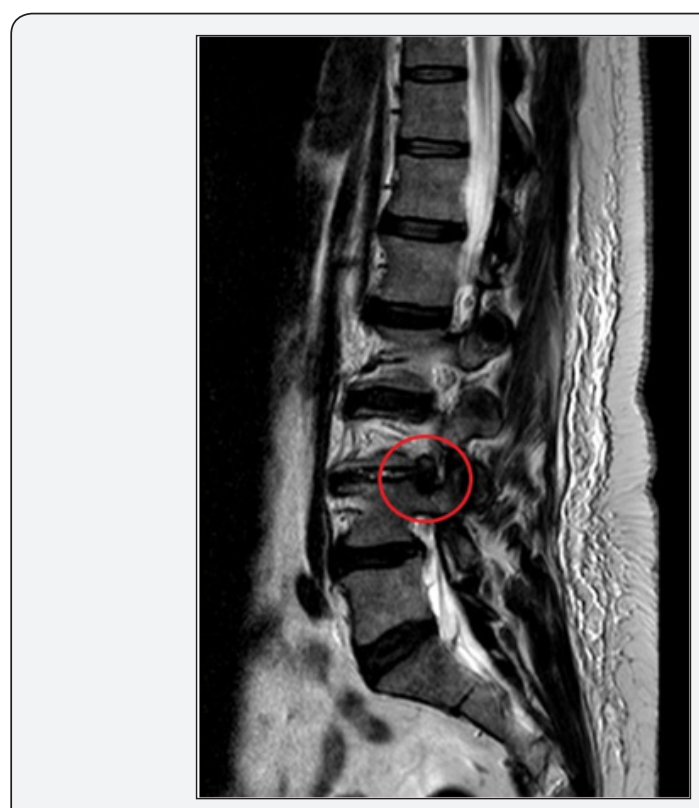

Figure 2A : Sagittal MRI

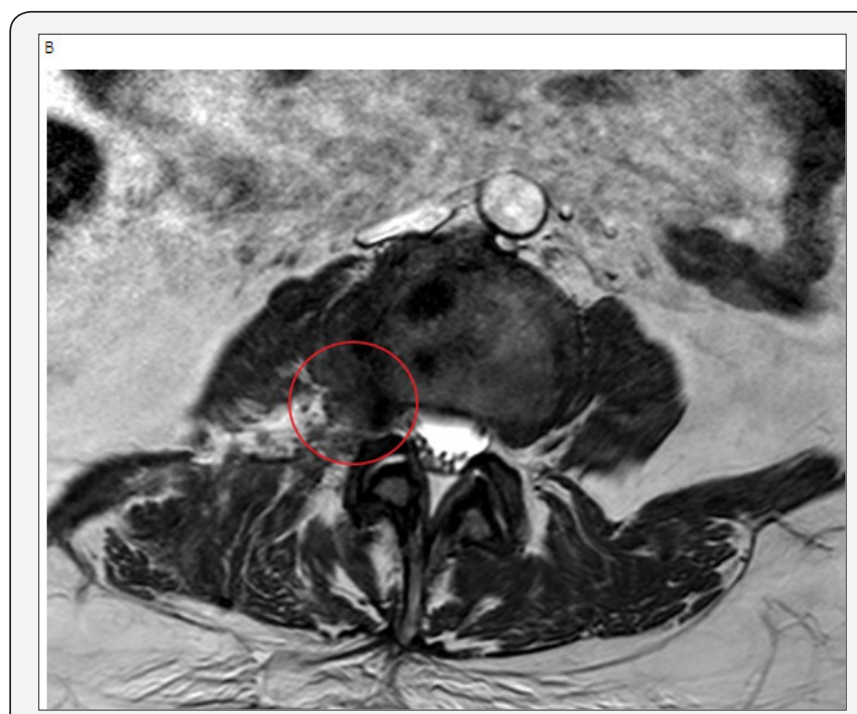

Figure 2B : axial MRI.

At this point it is necessary to move the endoscope's tip towards the cranial part of the foramen and identify the exit nerve root. This one is within soft tissue like fat and muscles and often it can be quite hard to find it. It is very important to remain with endoscope tip always close against the bony surface. Sometimes it can be useful to identify the upper transverse process which can help in indicating where to look for the exit nerve root: just inferior and medially to it. It is really a matter of a gentle dissection using an endoscopic probe and a coagulation tip. This last instrument, can also be used to identify the exit nerve by stimulating the surrounding soft tissue at a very low voltage. If we touch the nerve we will assist to some kind of 


\section{Open Access Journal of Neurology \& Neurosurgery}

motor response of the corresponding leg. Generally the nerve is found to be stretched out by the underlying prolapsed disk. Once the disk is visualized the nerve must be dissected apart and the protrusion removed. It is possible to check when an adequate decompression is achieved just seeing the nerve root moving freely up and down (Figure 2A-2G). At this point, after having checked for any bleeding, the working tube is withdrawn and the skin incision (8mm long) glued.

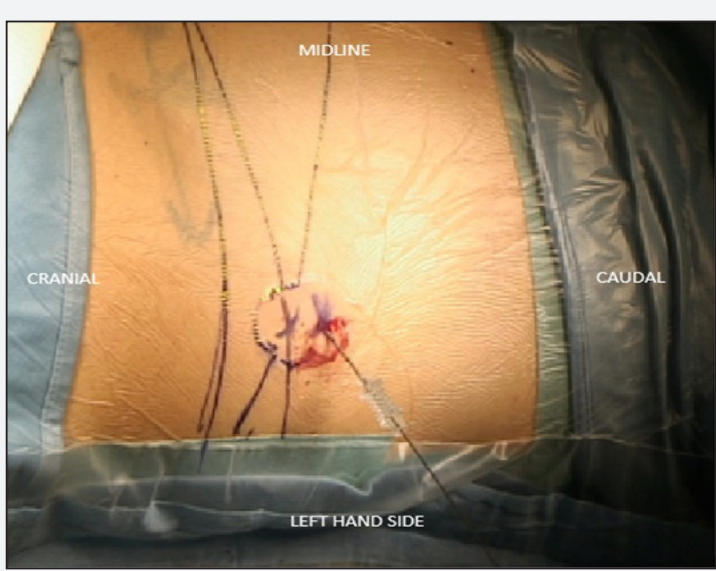

Figure 2c : Skin entry point.

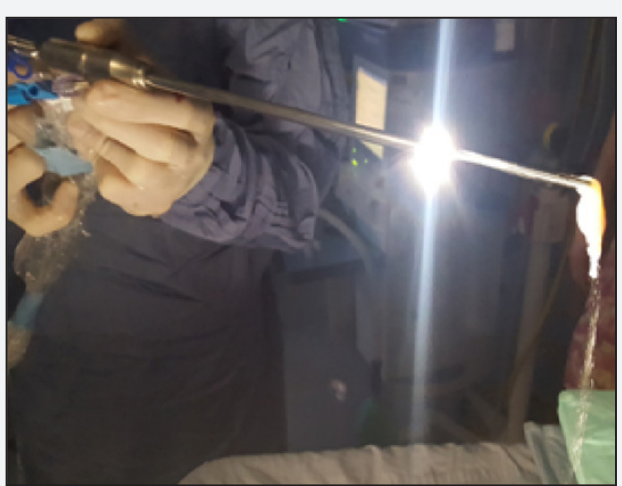

Figure 2d: Intraoperative view.

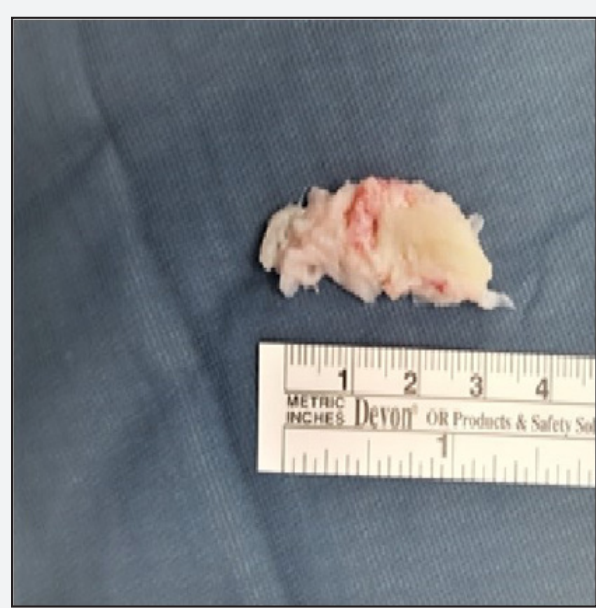

Figure 2E : Disk Removed.

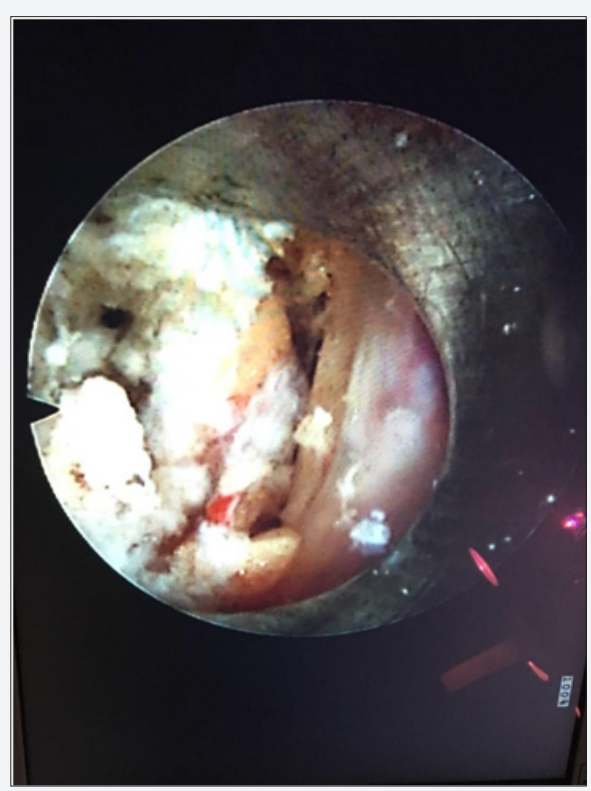

Figure 2F : Intraoperative nerve root view.

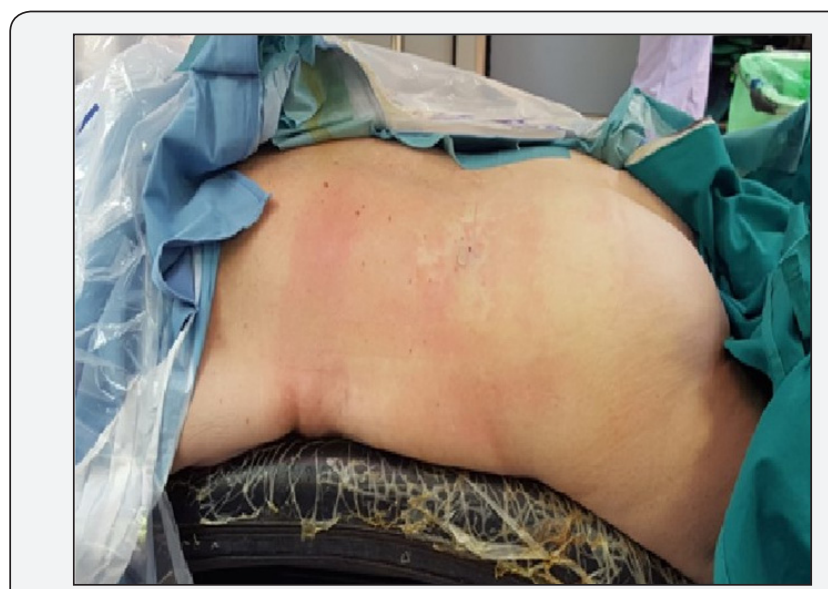

Figure 2G : Patient size.

\section{Results}

The median surgical time was of 120 minutes (range 55$145 \mathrm{~min}$.) in the microsurgical group with a median blood loss of $80 \mathrm{cc}$. In the endoscopic group the median operative time was 45 minutes (range 30-150min.) and negligible the blood loss. In both groups we have achieved a good control of the pain. In the microsurgical group we passed from a preoperative VAS of 7.29 respectively, to $4.21 ; 2.36 ; 1.36$ and 0.57 at $1,3,6$ and 12 months. In the endoscopic group the median VAS before surgery was 7.57 and at 1,3,6 and 12 months respectively $2.86 ; 1.86 ; 1.14$ and 0.57 (Graph 1A \& 1B). If, instead we consider the ODI results for the microsurgical group, they went down from $66.86 \%$ before surgery to $28.57 \%$ at 1 month; $12.86 \%$ at 3 months; $6.29 \%$ at 3 months and $1.71 \%$ at 12 months. Meanwhile the ODI in the endoscopic group improved from a preoperative value of $64.14 \%$ to $50 \%$ at 1 month; $27.14 \%$ at 3 months; $12.14 \%$ at 6 months and 
$3.57 \%$ at 12 months (Graph 2A \& 2B). From a complication point of view (Table 3 ) we had, in the microsurgical group: 1 wound infection (staphylococcus epidermidis) treated successfully with antibiotics; 1 post operative L4 paresis (3/5 MRC) improved completely after 3 weeks; 1 case of incomplete disk removal with persistent pain which required a second endoscopic approach three days later (Table 2). In the endoscopic treatment we registered only one but unusual complication. A patient woke up very slowly. He was hypothermic $\left(35^{\circ}\right)$ after a prolonged procedure (2.5 hours of surgery) and after having used 13 liters of normal saline for endoscopic irrigation. This was among one of the first cases we tried to do endoscopically.

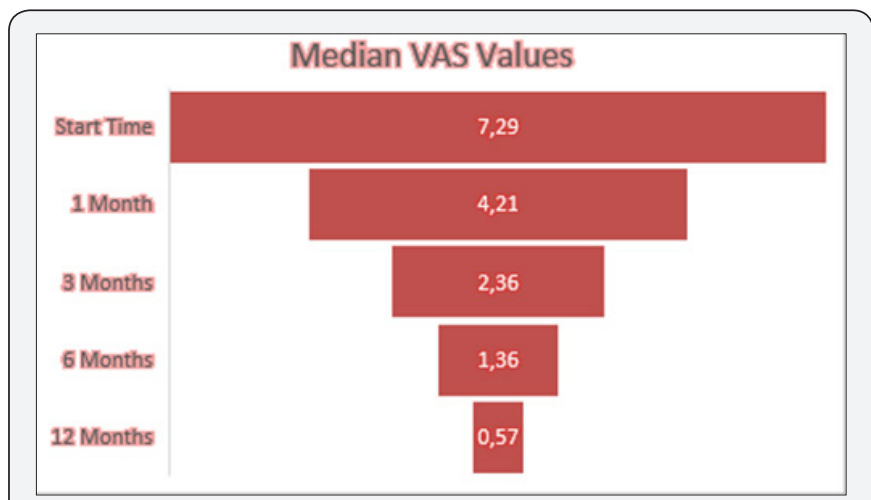

Graph 1A : Median VAS values microsurgical group.

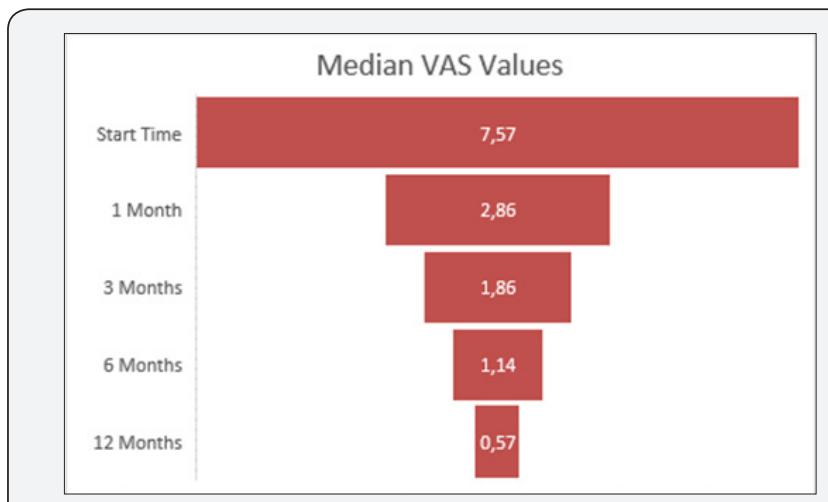

Graph 1B : Median VAS values endoscopic group.

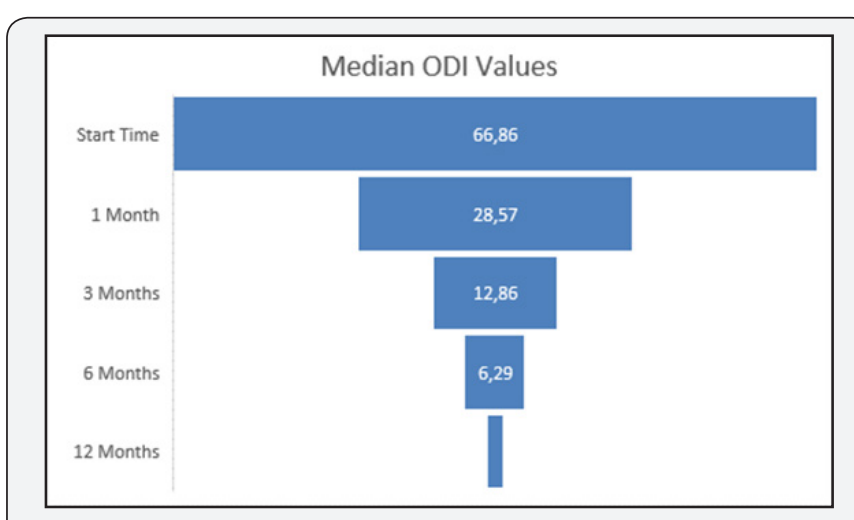

Graph 2A : Median VAS values microsurgical group.

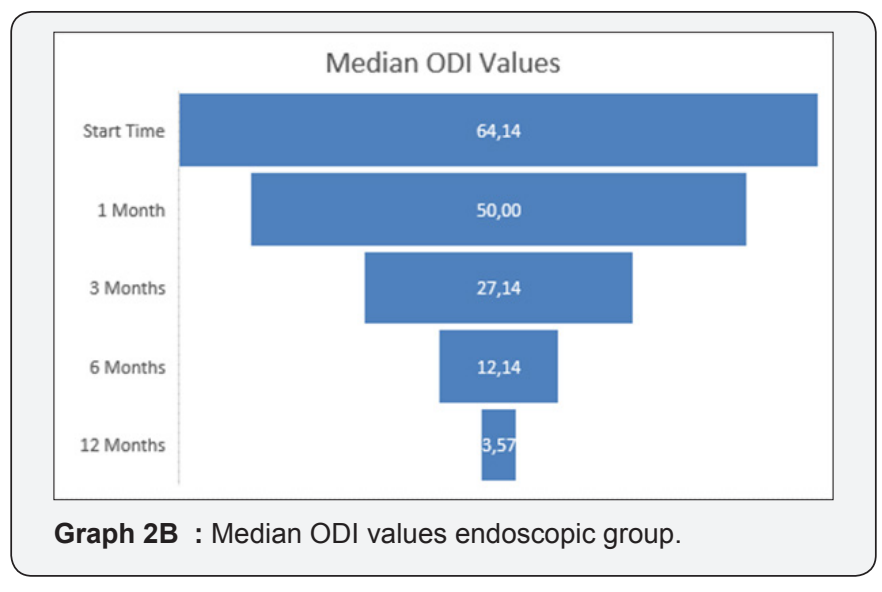

Table 3: Complications.

\begin{tabular}{|c|c|}
\hline Complications (22 cases) & Number of \\
\hline Cases & \\
\hline Wound Infection & 1 \\
\hline L4 Nerve Paresis & 1 \\
\hline Incomplete Disk Removal & 1 \\
\hline
\end{tabular}

\section{Discussion}

The extraforaminal lumbar disks prolapsed have an incidence around $7-12 \%$ of all lumbar disk protrusion [5]. The disk, is generally located at the external far end of the vertebral foramen and in almost $30 \%$ of the cases it points downwards [6]. This type of protrusion is compressing the exit nerve root and not the traversing one and it is acting along the nerve more distally, close to the ganglion. Probably this is the reason why these patients have a much more severe pain than somebody suffering for a standard medial-lateral disk protrusion. Very rarely, this type of pain, unlike the one which occurs in the standard disk protrusion, subsides by itself with time. The diagnosis of this pathology is necessarily with MRI because on a CT scan a far lateral disk can be missed. The surgical techniques we can utilize for the treatment of such particular protrusions are mainly two: interlaminar fenestration and lateral (far lateral) approach [68]. The first one is the same approach used for a typical lumbar microdiscectomy. This approach, however, implies the removal of a bigger amount of the facet joint if not all, in order to reach and decompress properly the exit nerve root in the portion just outside the foramen. Naturally this maneuver has got a high possibility of destabilizing the spine and a hardware fixation may be necessary during the same procedure or at a later stage. This is, however, for the surgeon the easiest route to reach the protruding disk: just following the disk space to its lateral border outside the spinal canal. A more elegant approach, in terms of spearing the normal anatomy, is using a paramedian or lateral route (about $6 \mathrm{~cm}$ from the midline). This approach does not require any bony removal and allows reaching the disk just passing (dilating) the muscles. It is a very anatomical technique, in terms of preserving structures but the surgeon works in a 
deep space within muscles and the skin incision can be quite long especially in obese patient $[7,8]$. Sometimes it can be also difficult and time consuming to find the offended nerve root with the constant risk of damaging it because it cannot be, so easily recognized. In this type of surgery there is the necessity of a bigger amount of nerve root manipulation just close to the ganglion zone and this is the reason why, often, these patients can present with a high number of temporary sensory leg disturbance in the postoperative period. It would be ideal if we could reach the prolapsed disk, identify the offended nerve root and free it using a percutaneous endoscopic approach.

No disruption of the anatomy, no bony sacrifice, minimal nerve root retraction, small skin incision and less postoperative surgical induced pain. For these reasons we have tried, once we have gained enough experience with the endoscopic procedures, this technique to tread such rare pathologies. With the percutaneous endoscopic approach the method is the same we use for a conventional percutaneous endoscopic transforaminal surgery. Here, anyway the target is not to enter the foramen but to reach with the endoscope its external inferior border (upper and lateral part of the pedicle). Once we are there we have to dissect and look for the exit nerve root. In consideration the patient is under general anesthesia without muscles relaxant, any stimulation to the nerve root will result in some kind of leg movement and also this can guide the surgeon. At the beginning can be quite difficult to identify the offended nerve and it is necessary the presence of two surgeons with the second one helping to stabilize the endoscope inside the working tube which is free among the muscle fibers and not anchored inside a bony canal, like in the standard transforaminal route. With experience, a single surgeon becomes enough. This type of procedure requires smaller skin incisions, minimal muscles dilatation thus resulting in less tissue damage than the traditional open technique and there is no differences in terms of wound size if the patient is obese or thin. In our series the results measured in terms of VAS and ODI are better for the cases performed by endoscopic approach. Interestingly we noticed two aspects: we had, less transient subjective post operative dysesthesia in the endoscopic group (19\%) versus $25 \%$ in the microsurgical one. All of them improved from a few days to a week. This is probably due to the possible manipulation of the ganglion during nerve root retraction. Secondly the leg pain which in the standard disk protrusion use to settle very soon after surgery, in the far lateral disk, generally it takes longer, a few days, to improve. We do not have an explanation for this observation, probably it concerns always the ganglion's disturbance. The number of complications we encountered, we believe, are very few. The patient we had to operate again was mainly due to an erroneous interpretation of the amount of disk removed. This is the reason why we like to have always a recent MRI before to perform any type of endoscopic approach.

\section{Conclusion}

The percutaneous endoscopic technique is definitively becoming a standard method in the treatment of lumbar disk prolapsed. Our series, although small, has stressed the utility of this technique also for the extraforaminal disks prolapsed and has shown that it can give similar result that the microsurgical technique as well as a lower rate of neuropathic dysfunction, a faster mobilization and a quicker return to a normal working life. Furthermore it may avoid the necessity of spinal fusion. However we cannot, for the type of study we conducted, make any stronger and definitive statement.

\section{References}

1. Lee JS, Kim HS, Jang JS, Jang IT (2016) Structural Preservation Percutaneous Endoscopic Lumbar Interlaminar Discectomy for L5-S1 Herniated Nucleus Pulposus. Biomed Res Int ; 2016: 6250247.

2. Yang JS, Zeng YS, Liu TJ, Hao DJ (2017) Full-endoscopic procedures versus traditional discectomy surgery for discectomy: a systematic review and meta-analysis of current global clinical trials. Pain Physician 20(7): E1123-E1124.

3. Vogelsang JP, Maier H (2008) Clinical results and surgical technique for the treatment of extreme lateral lumbar disc herniations: the minimallyinvasive microscopically assisted percutaneous approach. Zentralbl Neurochir 69(1): 35-39.

4. Yoshimoto M, Iwase T, Takebayashi T, Ida K, Yamashita T (2014) Microendoscopic discectomy for Far-Lateral lumbar disk erniation: less surgical invasiveness and minimum 2-year follow-up results. J Spinal Disord Tech 27(1): E1-E7.

5. Papavero L, Kothe R (2013) The translaminar approach for cranially extruded lumbar disc herniations. Oper Orthop Traumatol 25(1): 6-15.

6. Zheng C, Wu F, Cai L (2016) Transforaminal percutaneous endoscopic discectomy in the treatment of far-lateral lumbar disc herniations in children. Int Orton 40(6): 1099-1102.

7. Al-Khawaja DO, Mahasneh T, Li JC (2016) Surgical treatment of FarLateral lumbar disc herniation: a safe and simple approach. J Spine Surg 2(1): 21-24.

8. Choi KC, Kim JS, Park CK (2016) Percutaneous endoscopic lumbar discectomy as an alternative to open lumbar microdiscectomy for large lumbar disc herniation. Pain Physician 19(2): E291-E300.

9. Wang B, Lü G, Liu W, Cheng I, Patel AA (2012) Full-endoscopic interlaminar approach for the surgical treatment of lumbar disc herniation: the causes and prophylaxis of conversion to open. Arch Orthop Trauma Surg 132(11): 1531-1538. 
(C) (i) This work is licensed under Creative

(C) C. Commons Attribution 4.0 Licens
Your next submission with Juniper Publishers will reach you the below assets

- Quality Editorial service

- Swift Peer Review

- Reprints availability

- E-prints Service

- Manuscript Podcast for convenient understanding

- Global attainment for your research

- Manuscript accessibility in different formats

( Pdf, E-pub, Full Text, Audio)

- Unceasing customer service

Track the below URL for one-step submission https://juniperpublishers.com/online-submission.php 